\title{
IncHI plasmids, a dynamic link between resistance and pathogenicity
}

\author{
Minh-Duy Phan, John Wain \\ Tropical Microbiology, The Wellcome Trust Sanger Institute, Hinxton, Cambridge. CB10 1SA, United Kingdom
}

\begin{abstract}
Plasmids of incompatibility group (Inc) HI1 are important vectors of antibiotic resistance in both of the major causal agents of enteric fever: Salmonella enterica subspecies enterica serovar Typhi and S. Paratyphi A. In S. Typhi, IncHII plasmids appeared in the 1970s and spread globally. In some circumstances they are maintained within the bacterial population even in the absence of selection from antibiotics. The low cost associated with IncH plasmids in Salmonella is due, in part, to the presence of a plasmid gene encoding an $\mathrm{H}$-NS-like global regulator which acts co-operatively with chromosomally encoded $\mathrm{H}-\mathrm{NS}$. Very recently, IncHI1 plasmids have crossed from S. Typhi into S. Paratyphi A; the acquisition of drug resistance and possibly other phenotypic traits encoded by IncHI1 plasmids has increased the virulence potential of this neglected pathogen. There is no vaccine for S. Paratyphi A and resistance to the current drugs of choice, the fluoroquinolones, is also spreading rapidly. There is a conserved backbone to all IncH plasmids but variation occurs in regions of the plasmids associated with antibiotic resistance. These IncHI1 plasmids are allowing major human pathogens to sample genes available in their environment, the human gut, and will be maintained by enhancing the competitive advantage of the bacterial host. Therefore competition between closely related resistance plasmids will probably increase the transmission of enteric fever by enhancing the fitness of their bacterial hosts.
\end{abstract}

Key Words: IncHI1 plasmid, multidrug resistance, Typhi, pathogenicity

J Infect Developing Countries 2008; 2(4): 272-278.

Received 15 June 2008 - Accepted 30 June 2008

Copyright (c) 2008 Phan \& Wain. This is an open access article distributed under the Creative Commons Attribution License, which permits unrestricted use, distribution, and reproduction in any medium, provided the original work is properly cited.

\section{Introduction}

Salmonellosis is a major cause of morbidity and mortality in both humans and animals. Although precise figures on disease burden are not available, it is estimated that globally there are approximately 3 billion human cases per year. The disease syndrome is predominantly gastroenteritis (diarrhoea or vomiting) but invasion from the gut has a major impact on mortality [1]. While vaccines are not widely utilised, either because there is no vaccine or because of cost, antibiotics remain the major tool for managing invasive disease [2]. However, most cases occur in resource-poor regions of the world where resistance to antibiotics and the cost of second-line agents are of major concern for the management of invasive salmonellosis. In this review we will describe the extent of resistance in the most common invasive Salmonella serovars: Salmonella enterica serovar Typhi and S. Paratyphi A. We will then go on to discuss the molecular mechanisms by which these two distinct but closely related pathogens have acquired and now share multi-drug resistance
(MDR) to the antibiotics used for treatment. The main obstacle to current medical interventions is antibiotic resistance.

\section{Enteric fever: Typhoid fever and paratyphoid fever}

Typhoid fever is a systemic, febrile illness caused by the bacterium Salmonella enterica serovar Typhi (S. Typhi). Although, since the early 20th century, the provision of good sanitation in Europe and the USA has led to a decline in the recorded disease burden, enteric fever remains a major public health problem in many parts of the world, mostly in developing countries. Estimates, such as 21.6 million cases resulting in 216,500 deaths during the year 2000, are probably hopelessly inaccurate and the true burden, particularly in sub-Saharan Africa, is completely unknown. Without appropriate treatment, up to $20 \%$ of patients may develop and die of severe disease and life-threatening complications such as gastrointestinal perforation, toxaemia, meningitis or endocarditis [3]. Between 1 and 10\% of typhoid 
patients become chronic carriers; this is defined as excretion of $S$. Typhi in urine or stools for more than one year (reviewed in [2]).

A very similar but classically less severe disease, paratyphoid fever, is caused predominantly by $S$. Paratyphi A. Although previously estimated to cause approximately a quarter of the incidence of typhoid fevers [4], studies from India and Nepal suggest that paratyphoid fever may contribute half of all cases of enteric fever (reviewed in [5]). Passive, community based, culture-confirmed surveillance shows that the proportion of enteric fever caused by $S$. Paratyphi A infection varies, from $14 \%$ in Indonesia to $64 \%$ in southern China [6].

\section{Antibiotic resistance in Typhoidal Salmonellae}

Chloramphenicol was introduced for the treatment of typhoid fever in 1948. Although sporadic cases of chloramphenicol resistant typhoid fever were reported two years later, resistance to chloramphenicol took a long time to become established. The first reported outbreak of antibiotic resistant typhoid fever occurred in May 1972 in Kerala, India. Chloramphenicol resistance was demonstrated to be plasmid-borne in the $S$. Typhi isolated during the outbreak. In the same year, two other chloramphenicol resistant outbreaks were also documented, in Mexico and Vietnam, both caused by $S$. Typhi harbouring an IncH plasmid. The global spread of chloramphenicol resistant $S$. Typhi by the 1980 s forced a change of treatment to co-trimoxazole or ampicillin in many regions. Multidrug resistance (MDR), defined as resistance to all first-line antimicrobials (ampicillin, co-trimoxazole, and chloramphenicol), emerged gradually in S. Typhi. The first reported MDR outbreak occurred in late 1987 in China. In the next two years, there were reports of MDR $S$. Typhi strains from India, Pakistan and the Arabian Gulf. During the expansion of MDR $S$. Typhi, plasmids of incompatibility groups IncA, IncC and Incl were observed but failed to disseminate, whereas plasmids of the IncH group were seen repeatedly in outbreak cases and once acquired, conferred long-term resistance. Multidrug resistant S. Typhi strains harbouring IncHII plasmids are now globally distributed (reviewed in [1, 7]).

With the emergence of MDR, the fluoroquinolone antibacterials became the treatment of choice for typhoid fever. Under this new selective pressure, an increase in resistance to fluoroquinolones [8] and a decline in MDR strains in some regions [9] were observed. More recently, the emergence of high-level ciprofloxacin resistance in S. Typhi [1] and S. Paratyphi A [10, 11] has left treatment for resistant enteric fever dependent on third-generation cephalosporins and azithromycin [2]. While MDR S. Typhi strains have been isolated globally since the 1980s, S. Paratyphi A remained predominantly susceptible to antibiotics $[12,13]$. In recent years however, there has been an increasing incidence of MDR $S$. Paratyphi A, particularly in Asia. In Nepal the MDR rate in S. Paratyphi A was higher (7\%) than the rate in S. Typhi (5\%) [14]; in North India, MDR S. Paratyphi $A$ isolation was also increased [15]. For S. Paratyphi A infections imported into the USA, the only MDR cases were associated with a history of travel to Pakistan [16] In Europe, paratyphoid is almost entirely an imported disease but still acts as a reminder for the situation in endemic regions. In the UK, MDR S. Paratyphi A rose from 9\% in 1999 to $25 \%$ in 2001 in travellers, most of whom were returning from the Indian sub-continent [17].

\section{Molecular basis of multidrug resistance - IncHI1 plasmids}

Plasmids of the Enterobacteriaceae are categorized into groups based upon their ability (or inability) to co-exist within the same bacterial cell. Plasmids of the same incompatibility (Inc) group are related, with similar replication mechanisms and regulatory circuits for essential plasmid functions; they cannot survive together in the same bacterial cell [18] and so are considered to be incompatible. More than 30 incompatibility groups have been described.

The $\mathrm{H}$ incompatibility complex comprises two Inc groups, IncHI and IncHII, based on their similar $\mathrm{H}$-pilus structure [19]. All IncH plasmids are large molecules with sizes of $150 \mathrm{~kb}$ or more and all are temperature sensitive for conjugative transfer [20]. Based on restriction digestion, DNA-DNA hybridization studies and incompatibility studies, the IncHI group of plasmids has been divided into three subgroups, IncHI1, IncHI2 and IncHI3. Although these groups are incompatible with each other, there is minimal homology over the whole of the plasmid $[21,22]$. It seems, therefore, that only the replication apparatus is conserved between 
these plasmids and that there must be a wide variety of genes associated with IncHI1 replicons. To find plasmids with a reduced rate of transfer at body temperature $\left(37^{\circ} \mathrm{C}\right)$ in a human restricted pathogen is unexpected. The efficiency is optimal at $22^{\circ} \mathrm{C}$ to $30^{\circ} \mathrm{C}$ which suggests that IncHI 1 are potential vectors for the dissemination of genes among bacterial species in water and soil environments [23]. These plasmids have a wide host range which includes the Enterobacteriaceae and several Gram negative organisms of environmental significance. So why and how have these plasmids become established in typhoidal Salmonella?

The complete nucleotide sequences of three IncHI1 plasmids, R27 (180kb), pHCM1 (218 kb) and pAKU1 (212 kb), have been determined [2426]. R27, the prototype of the IncHI1 plasmids, was first isolated in the UK from $S$. Typhimurium in 1961. Very similar plasmids have subsequently been recovered from $S$. Typhi; pHCM1 originated from S. Typhi in Vietnam in 1993 and pAKU1 was from S. Paratyphi A strain AKU12601 from Pakistan in 2002. These three plasmids share a common backbone sequence (>99\% identity at the DNA level) including $83 \%$ of the pAKU1 sequence. This suggests a close evolutionary relationship and also the spread of these MDR plasmids from one human restricted Salmonella serovar to another.

\section{R27, the prototypical IncHI1 plasmid}

The prototypical IncHI1 plasmid is R27 which encodes resistance to tetracycline only. This plasmid has been intensively studied for over 20 years and, like all IncHI1 plasmids tested, R27 possesses three replication initiation proteins: RepHI1A, RepHI1B and RepFIA-like [27, 28]. RepHIA and RepHI1B have been shown to mediate plasmid replication and copy number control by binding of the Rep to the flanking repeat sequences (iterons) [29]. Both RepHIA and $\mathrm{RepHI} 1 \mathrm{~B}$ are specific for IncHI1 plasmids. Minimal replicon analysis suggests that either of the two Rep proteins can efficiently replicate the entire plasmid but the RepFIA-like replication initiation protein of R27 is unable to stably replicate the entire plasmid under challenge conditions [28]. This RepFIA-like protein, however, confers oneway compatibility between the HI1 and F plasmids.
This is due to a short region of similarity in the essential replication protein of $F$ (gene E) [30].

Conjugative transfer in IncHI1 plasmids is of special scientific interest, not only because the conjugative machinery has to accommodate the transfer of a very large plasmid, but also because of the way conjugation is regulated. There are two transfer regions (Tra1 and 2) which are essential for plasmid function but widely separated. With the full sequence of R27 we now know that the Tra1 region is located between the coordinates 98 and $117 \mathrm{~kb}$ and contains 14 predicted coding sequences (CDSs), only nine of which encode essential transfer genes. The CDSs are organised into three operons: $H, R$ and $F[31,32]$. The origin of transfer (oriT) was also identified in this region, between the $\mathrm{H}$ and $\mathrm{R}$ operons. The $\mathrm{R}$ and $\mathrm{F}$ operons encode the mating pair formation (Mpf) components and show sequence homology to the IncF transfer system. The $\mathrm{H}$ operon contains genes encoding for relaxosome proteins (traJ and tral), the coupling protein (traG) and other proteins not essential for transfer. The coupling protein was shown to be ancestrally related (low identity) to that of IncP plasmids. The Tra2 region is sixtythree kilobases away from Tra1, spanning over 36 $\mathrm{kb}$ and containing $28 \mathrm{CDSs}$. Except for four CDSs involved in partition function, the remaining CDSs are arranged into 3 operons encoding for $\mathrm{Mpf} / \mathrm{H}$ pilus components ( $A C$ and $A N$ operons) and entry exclusion proteins ( $Z$ operon) [31] [33]. A total of 11 genes in this region have been demonstrated by mutational and genetic analysis to be essential for conjugative transfer [34]. Similar to Tra1, this region also exhibits a mosaic of IncF-related (Mpf genes) and IncP-related (trhA and trhP) sequences. In summary, the conjugative transfer system of R27 consists of 20 essential genes located in 2 separate regions and the Mpf system shares a common ancestry with the IncF lineage. The relaxosome, pilin and peptidase genes show closer relatedness to IncP plasmids.

\section{Temperature dependent conjugation and H-NS}

An interesting phenotype seen with R27 and R27-like plasmids is that they regulate their own conjugative transfer in a temperature-dependent manner. This has implications for transmission and persistence of the resistance phenotype in the typhoidal salmonella population. The thermoregulation of transfer is a multi-level 
regulatory process involving the thermo-dependent mating pair formation, the global regulatory protein $\mathrm{H}-\mathrm{NS}$ and a thermo-modulator $\mathrm{Hha}$. The $\mathrm{H}$ pilus is synthesized at an optimal temperature of $27^{\circ} \mathrm{C}$ by extrusion from the cell surface. At $37^{\circ} \mathrm{C}$, the morphology of $\mathrm{H}$ pili remains stable whilst the formation of mating aggregates is inhibited [35]. No pili can be observed by transmission electron microscopy at $37^{\circ} \mathrm{C}$, in agreement with expression data from other studies. H-NS-like and Hha-like proteins on R27 repress transcription of several CDSs in both Tra1 and Tra2 regions at the nonpermissive temperatures, $\left(20-33^{\circ} \mathrm{C}\right)$. Band shift assays suggest the inhibition mechanism of $\mathrm{H}-\mathrm{NS}$ involves interaction with the promoter regions from Tra1 and Tra2 and with the origin of replication (oriT) sequence. The presence of Hha facilitates the generation of higher-order hetero-oligomers of $\mathrm{H}-\mathrm{NS}$ that interact with DNA and may alter, in a very subtle way, the expression of chromosomal genes of the bacterial host for these plasmids [36].

\section{IncHI1 plasmids in S. Typhi}

The stable maintenance of IncHI1 plasmids in S. Typhi occurred throughout the development of antibiotic resistance in S. Typhi. The first reported S. Typhi harbouring an IncH plasmid was resistant to chloramphenicol, tetracycline, streptomycin, and sulphonamides and was isolated during a large outbreak of resistant typhoid fever in Mexico City [37]. Two other outbreaks of IncHI1 carrying $S$. Typhi also began in the same year in Vietnam and India. The plasmids from the three outbreaks were all of the IncHI1 group and all the same size, but they differed in the phenotype conferred to the bacterial host in resistance to mercury and ability to utilise citrate [21]. The spread of chloramphenicol-resistant $S$. Typhi forced the change in treatment to either co-trimoxazole or ampicillin in several regions, including India and Vietnam [38]. This then led to the emergence of multiple drug resistant (MDR) S. Typhi and in 1988 in Kashmir the first reported MDR outbreak of typhoid fever occurred [39]. Multidrug resistant S. Typhi was also reported from Egypt in the same year [40], Shanghai in 1988-1989 [41], Qatar in 1988 [42] and eastern India in 1989 [43]. Several isolates from these regions were shown to carry plasmids of high molecular weights $(150 \mathrm{~kb}$ to $185 \mathrm{~kb})$. The MDR S. Typhi spread globally and by
1998 IncHI1 plasmids could be isolated from MDR S. Typhi worldwide [44].

\section{The movement of IncHI1 plasmid into $S$. Paratyphi A}

Plasmid-mediated multidrug resistance was, until recently, uncommon in $S$. Paratyphi $A$. However MDR S. Paratyphi A isolates in Bangladesh and Karachi have now been shown to harbour a large transferable plasmid of $140 \mathrm{MDa}$ ( $212 \mathrm{~kb})$. Recently, a 212-kb plasmid of IncHI1 isolated from a $S$. Paratyphi $A$, identified at the Aga Khan University Hospital in Karachi, Pakistan, was fully sequenced and annotated [26]. Sequence comparison showed high levels of identity of this plasmid (pAKU1) with the two other IncHI1 plasmids, pHCM1 and R27. A shared IncHI1 backbone of $164.4 \mathrm{~kb}$ was identified, including the IncHI1 incompatibility locus, the three replicons (RepHIIA, RepHI1B and RepFIA) and genes involved in the core plasmid function of replication, maintenance and conjugative transfer as well as many hypothetical genes.

The pAKU1 plasmid was among 67 PCRdetermined IncHI1 plasmids (out of 68 MDR S. Paratyphi A isolates) from Pakistan in 2002-2004. The high prevalence of IncHI1 plasmids in this area strongly suggests a successful jump of IncHI1 plasmids into the $S$. Paratyphi A population. Further information is needed to assert whether these IncHI1-bearing S. Paratyphi A isolates are the result of a clonal expansion of a single successful combination of $S$. Paratyphi A background and IncHI1 plasmid, or whether IncHI1 plasmids have successfully invaded multiple clones of $S$. Paratyphi $A$ in the population. The next stage of this research will be to type the background strains from a global collection of MDR S. Paratyphi A.

\section{Plasmid evolution}

Acquiring a large plasmid (such as IncHI1) is commonly believed to impose a fitness burden on the bacterial host. However, it has been shown in the laboratory environment that co-evolution occurs in plasmid-harbouring bacteria, resulting in increased fitness over the plasmid-free ancestor [45] [46]. The evolved plasmids also confer a fitness advantage to new cells, suggesting that the phenomenon is plasmid encoded [46]. If this adaptation occurs under natural conditions, then 
once a conjugative plasmid becomes established in a bacterial population, it will remain even if the original selection (antibiotic usage) is removed. Furthermore, the acquisition of a newly adapted plasmid, as seen in S. Paratyphi A, might help the new host bacterium to spread due to a fitness advantage, other than resistance, thus amplifying the plasmid.

Although IncHI1 plasmids are not commonly found in organisms other than S. Typhi, their thermo-sensitive transmission and relatively wide host range suggest an origin from soil bacteria. Chloramphenicol resistant outbreaks in 1972, the subsequent global spread of IncHI1 plasmids in $S$. Typhi and their recent acquisition by $S$. Paratyphi A may represent the situation suggested above. Studies looking at the natural evolution of clinically important plasmids have been predominantly phenotypic and a definitive link between enhanced bacterial fitness and acquired antibiotic resistance has proved elusive. In the genomic era, however, if global strain collections from countries where antibiotic resistance is endemic can be analysed using data derived from the new sequencing technologies such as 454 and Solexa, the linking of plasmid-borne genes to enhanced bacterial fitness should be feasible, if such a link exists [47], as well as to a reduction in biological cost [48].

Figure 1. Genetic map of IncHI1 plasmid pHCM1. Genetic map of pHCM1 with highlighted features: yellow - transfer regions; blue - other plasmid biology functions (replication, partition and post-segregation killing); green - mobile elements; red - resistant genes/operons; and grey - regions acquired by pHCM1 but not found in the prototype plasmid R27.

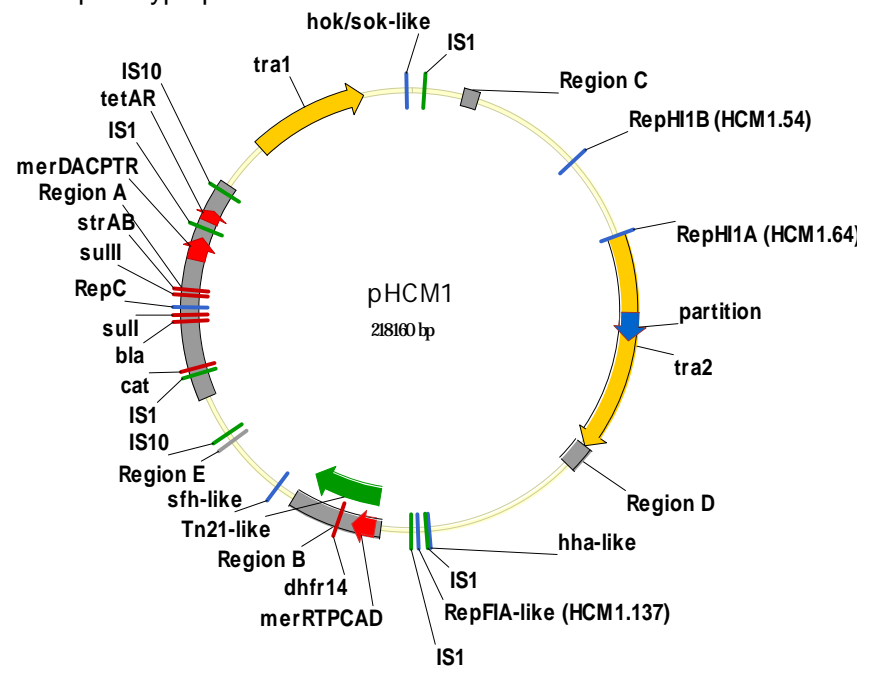

\section{Conclusion}

The IncHI1 plasmids found in S. Typhi today have been co-evolving with their bacterial host at least since the 1970s. They are still present in many areas of the world, even though resistance to the antibiotics of choice for enteric fever (the fluoroquinolones) is not encoded on IncHI1 plasmids. The plasmids (but not always the resistance phenotype) are stably maintained in antibiotic-free laboratory media. These large plasmids confer no detectable cost to S. Typhi. This easy co-existence requires the integration of plasmid and bacterial gene expression regulation networks. A plasmid encoded nucleoid-associated protein (H-NS-like protein) confers a stealth mechanism through which A+T-rich R27-like plasmids can enter Salmonella hosts with minimal impact on global gene expression patterns [48]. This strategy has the effect of smoothing the initial entry of extra-chromosomal genetic material, mediating the process of adaptation and integration of this new element into the regulatory network. There is, however, something deeper, some subtle regulatory balance, or imbalance, which confers an advantage associated with the presence of an IncHI1 plasmid. The possession of an R27-like IncHI1 plasmid was shown to increase the level of survival inside monocytic cell lines in $S$. Typhimurium [48] and to allow higher levels of bacteraemia for S. Typhi during typhoid fever [49]. This suggests a role of this plasmid in the enhancement of bacterial survival and multiplication in vivo.

\section{Acknowledgments}

John Wain and Duy Phan are supported by the Wellcome Trust of Great Britain. We thank Gemma Langridge for proof reading the article.

\section{References}

1. Hasan R, Cooke FJ, Nair S, Harish BN, Wain J (2005) Typhoid and paratyphoid fever. Lancet 366:1603-1604.

2. Parry CM (2004) The treatment of multidrug-resistant and nalidixic acid-resistant typhoid fever in Viet Nam. Trans R Soc Trop Med Hyg 98: 413-422.

3. Le TA, Lejay-Collin M, Grimont PA, Hoang TL, Nguyen TV, Grimont F and Scavizzi MR (2004) Endemic, epidemic clone of Salmonella enterica serovar typhi harboring a single multidrug-resistant plasmid in Vietnam between 1995 and 2002. J Clin Microbiol 42: 3094-3099.

4. Crump JA, Luby SP and Mintz ED (2004) The global burden of typhoid fever. Bull World Health Organ 82: 346-353.

5. Bhan, MK, Bahl R and Bhatnagar S (2005) Typhoid and paratyphoid fever. Lancet 366: 749-762. 
6. Ochiai RL, Wang X, von Seidlein L, Yang J, Bhutta ZA, Bhattacharya SK, Agtini M, Deen JL, Wain J, Kim DR, Ali M, Acosta CJ, Jodar L and Clemens JD (2005) Salmonella Paratyphi A rates Asia. Emerg Infect Dis 11: 1764-1766

7. Wain J, and Kidgell C (2004), The emergence of multidrug resistance to antimicrobial agents for the treatment of typhoid fever. Trans R Soc Trop Med Hyg 98: $423-430$

8. Wain J, Hoa NTT, Chinh NT, Vinh H, Everett MJ, Diep TS, Day NPJ, Solomon T, White NJ, Piddock LJV and Parry CM (1997) Quinolone-resistant Salmonella typhi in Viet Nam: Molecular basis of resistance and clinical response to treatment Clin Infect Diseases 25: 1404-1410

9. Dutta S, Sur D, Manna B, Bhattacharya SK, Deen JL and Clemens JD (2005) Rollback of Salmonella enterica serotype Typhi resistance to chloramphenicol and other antimicrobials in Kolkata, India. Antimicrob Agents Chemother 49: 1662-1663

10. Joshi S, and Amarnath SK (2007) Fluoroquinolone resistance in Salmonella typhi and $S$ paratyphi $A$ in Bangalore, India. Trans R Soc Trop Med Hyg 101: 308310

11. Nair S, Unnikrishnan M, Turner K, Parija SC, Churcher C, Wain J and Harish N (2006) Molecular analysis of fluoroquinolone-resistant Salmonella Paratyphi $A$ in India. Emerg Infect Dis 12: 489-491

12. Kapil, A, Sood S, Reddaiah VP, Das B and Seth P (1997) Paratyphoid fever due to Salmonella enterica serotype paratyphi A. Emerg Infect Dis 3: 407

13. Woods CW, Murdoch DR, Zimmerman MD, Glover WA, Basnyat B, Wolf L, Belbase RH and Reller LB (2006) Emergence of Salmonella enterica serotype Paratyphi $A$ as a major cause of enteric fever in Kathmandu, Nepal. Trans R Soc Trop Med Hyg 100: 1063-1067

14. Pokharel BM, Koirala J, Dahal RK, Mishra SK, Khadga PK and Tuladhar NR (2006) Multidrug-resistant and extended-spectrum beta-lactamase (ESBL)-producing Salmonella enterica (serotypes Typhi and Paratyphi A) from blood isolates in Nepal: surveillance of resistance and a search for newer alternatives. Int J Infect Dis 10: 434-438

15. Mohanty S, Renuka K, Sood S, Das BK and Kapil A (2006) Antibiogram pattern and seasonality of Salmonella serotypes in a North Indian tertiary care hospital. Epidemiology and Infection 134: 961-966

16. Gupta SK, Medalla F, Omondi MW, Whichard JM, Fields PI, Gerner-Smidt P, Patel NJ, Cooper KL, Chiller TM and Mintz ED (2008) Laboratory-based surveillance of paratyphoid fever in the United States: travel and antimicrobial resistance. Clin Infect Dis 46: 1656-63

17. Threlfall EJ, Fisher IST, Berghold C, Gerner-Smidt P, Tschape H, Cormican M, Luzzi I, Schnieder F, Wannet W, Machado J and Edwards G (2003) Trends in antimicrobial drug resistance in Salmonella enterica serotypes Typhi and Paratyphi A isolated in Europe, 1999-2001 International Journal of Antimicrob Agents 22: 487-491

18. Novick, RP (1987) Plasmid incompatibility. Microbiol Rev 51: 381-395

19. Taylor DE, and Grant RB (1977) Incompatibility and surface exclusion properties of $\mathrm{H} 1$ and $\mathrm{H} 2$ plasmids. $\mathrm{J}$ Bacteriol 131: 174-178
20. Taylor DE and Levine JG (1980) Studies of temperaturesensitive transfer and maintenance of $\mathrm{H}$ incompatibility group plasmids. J Gen Microbiol 116: 475-484

21. Smith HR, Humphreys GO, Grindley ND, Grindley JN and ES Anderson (1973) Molecular studies of an fi+ plasmid from strains of Salmonella Typhimurium. Mol Gen Genet 126: $143-51$

22. Whiteley $M$ and Taylor DE (1983) Identification of DNA homologies among $\mathrm{H}$ incompatibility group plasmids by restriction enzyme digestion and Southern transfer hybridization. Antimicrob Agents Chemother, 24: 194-200

23. Maher, D, Sherburne R and Taylor DE (1993) H-pilus assembly kinetics determined by electron microscopy. J Bacteriol 175: 2175-2183

24. Parkhill J, Dougan G, James KD, Thomson NR, Pickard D, Wain J, Churcher C, Mungall KL, Bentley SD, Holden MT, Sebaihia M, Baker S, Basham D, Brooks K, Chillingworth T, Connerton P, Cronin A, Davis P, Davies RM, Dowd L, White N, Farrar J, Feltwell T, Hamlin N, Haque A, Hien TT, Holroyd S, Jagels K, Krogh A, Larsen TS, Leather S, Moule S, O'Gaora P, Parry C, Quail M, Rutherford K, Simmonds M, Skelton J, Stevens K, Whitehead S and Barrell BG ( 2001) Complete genome sequence of a multiple drug resistant Salmonella enterica serovar Typhi CT18. Nature 413: 848-852

25. Sherburne CK, Lawley TD, Gilmour MW, Blattner FR, Burland V, Grotbeck E, Rose DJ and Taylor DE( 2000) The complete DNA sequence and analysis of R27, a large IncHI plasmid from Salmonella typhi that is temperature sensitive for transfer. Nucleic Acids Res 28: 177-186

26. Holt KE, Thomson NR, Wain J, Phan MD, Nair S, Hasan $R$, Bhutta ZA, Quail MA, Norbertczak $H$, Walker D, Dougan G and Parkhill J (2007) Multidrug-resistant Salmonella enterica serovar Paratyphi A harbour IncHI1 plasmids similar to those found in serovar Typhi. J Bacteriol 189: 4257-4264

27. Couturier M, Bex F, Bergquist PL and Maas WK ( 1988) Identification and classification of bacterial plasmids. Mol Biol Rev 52: 375-395

28. Gabant P, Chahdi AO and Couturier M (1994) Nucleotide Sequence and Replication Characteristics of RepHI1B: A Replicon Specific to the IncHI1 Plasmids. Plasmid 31: 111-120

29. Newnham PJ and Taylor DE (1994) Molecular analysis of RepHIA, a minimal replicon of the IncHI1 plasmid R27. Mol Microbiol 11: 757-768

30. Taylor DE, Chumpitaz JC and Goldstein F (1985) Variability of IncHI1 plasmids from Salmonella typhi with special reference to Peruvian plasmids encoding resistance to trimethoprim and other antibiotics. Antimicrob Agents Chemother 28: 452-455

31. Alonso G, Baptista K, Ngo T and Taylor DE (2005) Transcriptional organization of the temperature-sensitive transfer system from the IncHI1 plasmid R27. Microbiology 151: 3563-3573

32. Lawley TD, Gilmour MW, Gunton JE, Standeven LJ and Taylor DE (2002) Functional and Mutational Analysis of Conjugative Transfer Region 1 (Tra1) from the IncHI1 Plasmid R27. J Bacteriol 184: 2173-2180

33. Gunton JE, Ussher JER, Rooker MM, Wetsch NM, Alonso $G$ and Taylor DE (2008) Entry exclusion in the 
IncHI1 plasmid R27 is mediated by EexA and EexB. Plasmid 59: 86-101

34. Lawley TD, Gilmour MW, Gunton JE, Tracz DM and Taylor DE (2003) Functional and Mutational Analysis of Conjugative Transfer Region 2 (Tra2) from the IncHI1 Plasmid R27. J Bacteriol 185: 581-591

35. Maher D and Taylor DE (1993) Host range and transfer efficiency of incompatibility group $\mathrm{HI}$ plasmids. Can $\mathrm{J}$ Microbiol 39: 581-587

36. Forns N, Banos RC, Balsalobre C, Juarez A and Madrid C (2005) Temperature-Dependent Conjugative Transfer of R27: Role of Chromosome- and Plasmid-Encoded Hha and H-NS Proteins. J Bacteriol 187: 3950-3959

37. Gangarosa EJ, Bennett JV, Wyatt C, Pierce PE, Olarte J, Hernandes PM, Vazquez $V$ and Bessudo D (1972) An epidemic-associated episome? J Infect Dis 126: 215-218

38. Butler T, Rumans L and Arnold K (1982) Response of typhoid fever caused by chloramphenicol-susceptible and chloramphenicol-resistant strains of Salmonella typhi to treatment with trimethoprim-sulfamethoxazole. Rev Infect Dis 4: p551-561

39. Kamili MA, Ali G, Shah MY, Rashid S, Khan S and Allaqaband GQ (1993) Multiple drug resistant typhoid fever outbreak in Kashmir Valley. Indian J Med Sci 47: 147-151

40. Mikhail IA, Haberberger RL, Farid Z, Girgis NI and Woody JN (1989) Antibiotic-multiresistant Salmonella typhi in Egypt. Trans R Soc Trop Med Hyg 83: 120

41. Zhang $L$ (1991) [Mechanism of multiresistant Salmonella typhi]. Chung.Hua.I.Hsueh.Tsa.Chih.Taipei 71: 314-317

42. Uwaydah AK, Matar I, Chacko KC and Davidson JC (1991) The emergence of antimicrobial resistant Salmonella typhi in Qatar: epidemiology and therapeutic implications. Trans R Soc Trop Med Hyg 85: 790-792

43. Anand AC (1993) The anatomy of an epidemic (the final report on an epidemic of multidrug resistant enteric fever in eastern India). Trop Gastroenterol 14: 21-27
44. Hampton MD, Ward LR, Rowe B and Threlfall EJ (1998) Molecular fingerprinting of multidrug-resistant Salmonella enterica serotype Typhi. Emerg Infect Dis 4: 317-320

45. Dahlberg $C$ and Chao $L$ (2003) Amelioration of the Cost of Conjugative Plasmid Carriage in Escherichia coli K12. Genetics 165: 1641-1649

46. Dionisio F, Conceição IC, Marques ACR, Fernandes L and Gordo I (2005) The evolution of a conjugative plasmid and its ability to increase bacterial fitness. Biology Letters 1: 250-252

47. Wain J, Nga LTD, Kidgell C, James K, Fortune S, Diep TS, Ali T, Gaora PO, Parry C, Parkhill J, Farrar J, White NJ and Dougan G (2003) Molecular analysis of incHI1 antimicrobial resistance plasmids from Salmonella serovar Typhi strains associated with typhoid fever. Antimicrob Agents Chemother 47: 2732-2739

48. Doyle M, Fookes M, Ivens A, Mangan MW, Wain $\mathrm{J}$ and Dorman CJ (2007) An H-NS-like stealth protein aids horizontal DNA transmission in bacteria. Science 315: 251-252

49. Wain J, Diep TS, Ho VA, Walsh AM, Hoa NTT, Parry CM and White NJ (1998) Quantitation of Bacteria in Blood of Typhoid Fever Patients and Relationship between Counts and Clinical Features, Transmissibility and Antibiotic Resistance. J Clin Microbiol 36: 1683-1687

Corresponding Author: John Wain, The Wellcome Trust Sanger Institute, Wellcome Trust Genome Campus, Hinxton, Cambridge, CB10 1SA, UK, Tell: +44 (0) 1223 834244, Fax: +44 (0) 1223 494919, Email: jw5@sangeracuk

Conflict of interest: No conflict of interest is declared 